\title{
Manual de Simplificação do Trabalho
}

\author{
JoSÉ RODRIGUẹs DE SENNA
}

\section{III}

ANÁLISE DO VOLUME DO TRABALHO

31 - COMO COLETAR DADOS DE VOLUME

A análise do volume do trabalho completa o conjunto de fatos que o chefe precisa reunir a fim de poder tomar decisões eficazes em matéria de simplificação do trabalho. Essa análise não exige o emprêgo de técnicas estatísticas avançadas. Trata-se, na maioria dos casos, de simples contagem e de cálculos aritméticos comuns.

311. Especificação dos dados a coletar

- Chefe

a) Preparar, com base na análise do QDT e do Gráfico de Seqüência, uma especificação do que deve ser contado.

Observação - A coleta de dados de volume tem por objetivo ajudar a responder determinadas perguntas. Portanto, antes de especificar os dados, o chefe deve procurar definir bem as questões a resolver. Em seguida, indagará: que dados precisarei para responder a essas questões. Em geral, ao analisar o QDT e o Gráfico de Seqüência, surgem questões como estas, que originam a coleta de dados:

- o volume justifica a especialização desta tarefa?

- o volume justifica a consolidação de tarefas?

- o volume justifica a execução dêste passo?

- o volume justifica divisão do trabalho?

- qual o tempo médio para produzir uma unidade da tarefa $\mathrm{X}$ ?

— o volume justifica mecanização?

- há distribuição equitativa da carga de trabalho?

- há correspondência entre volume e capacidade de execução?

b) Definir as unidades para efeito de contagem.

Observação - Em geral não existe dificuldade na definição da unidade de contagem. Ela se refere a coisas tais como - guia de 
exame emitida, carta protocolada, associado atendido no balcão, documento arquivado, telefonema atendido, comprovante revisto, processo informado etc. Todavia, é desejável que se verifique antecipadamente o assunto, para evitar perda de tempo e esfôrço que poderá resultar, por exemplo, da contagem de coisas heterogêneas.

312. Seleção do método de coleta

- Chefe

a) Estudar e definir antecipadamente o melhor método para coletar cada tipo de dado.

Observação - Um pouco de raciocínio do chefe a êste respeito pode evitar desperdício de tempo e de esfôrço. Sempre que possível, deve-se colher os dados com base em registros já existentes, evitando-se a criação de sobrecarga de serviço. Eis alguns exemplos de métodos de contagem que podem economizar tempo e esfôrço:

- utilizar registros estatísticos já existentes (ex.: os boletins de produção em uso no IAPI);

- obter a diferença entre números em série de formulários ou documentos;

- contagem por amostra;

- pesagem;

- medição (ex.: medir com régua uma gaveta ou pilha de fichas ou documentos);

- manter registros durante certo período (ex.: um informante assinala num papel cada atendimento no balcão).

b) Preparar os meios necessários à coleta e ao registro dos dados.

Observação - A idéia dominante deve ser facilitar ao funcionário a coleta dos dados. Os meios a utilizar são os mais variados e caberá à engenhosidade do chefe prepará-los, de acôrdo com o caso. Exemplos: se quiséssemos apurar o número de linhas, em média, das Comunicações de Serviços, poderíamos preparar um gabarito, para evitar a contagem, linha a linha, em cada uma; se fôsse o caso de verificar quantas consultas são feitas em determinado fichário, talvez fôsse o caso de prender um papel na parte externa da gaveta, para nêle assinalar, com pequenos traços, as consultas, para contar as reclamações recebidas, por espécie, poderímos preparar uma fôlha, com as principais espécies, já registradas, de modo que o atendente apenas assinalasse cada uma, acrescentando as não previstas; e assim por diante. 
c) Instruir devidamente os funcionários encarregadcs da coleta, marcando o respectivo prazo.

d) Supervisionar a coleta dos dados.

\section{2 - COMO FAZER O QUADRO ESTATÍ́STICO}

321. Tratamento dos dados

- Chefe

a) Criticar as apurações, verificando os registros de totais e dos respectivos períodos.

b) Calcular a média de unidades por semana.

Observação - Quase sempre há vantagem nessa estimativa do volume em base semanal, visto que as estimativas de tempo do QDT são nessa base. A conversão consistirá, na maioria dos casos, em dividir a média mensal por quatro.

c) Calcular a média de tempo por unidade.

Observação - Para êsse cálculo, verificar no QDT o tempo semanal consumido na execução da tarefa e dividí-lo pela média de unidades produzidas por semana. Se a unidade corresponder apenas a uma parte da tarefa, usar outra estimativa de tempo que não a do QDT.

322. Preparo do quadro estatístico

- Chefe

a) Preparar quadro estatístico com os dados classificados e resumidos. Exemplo:

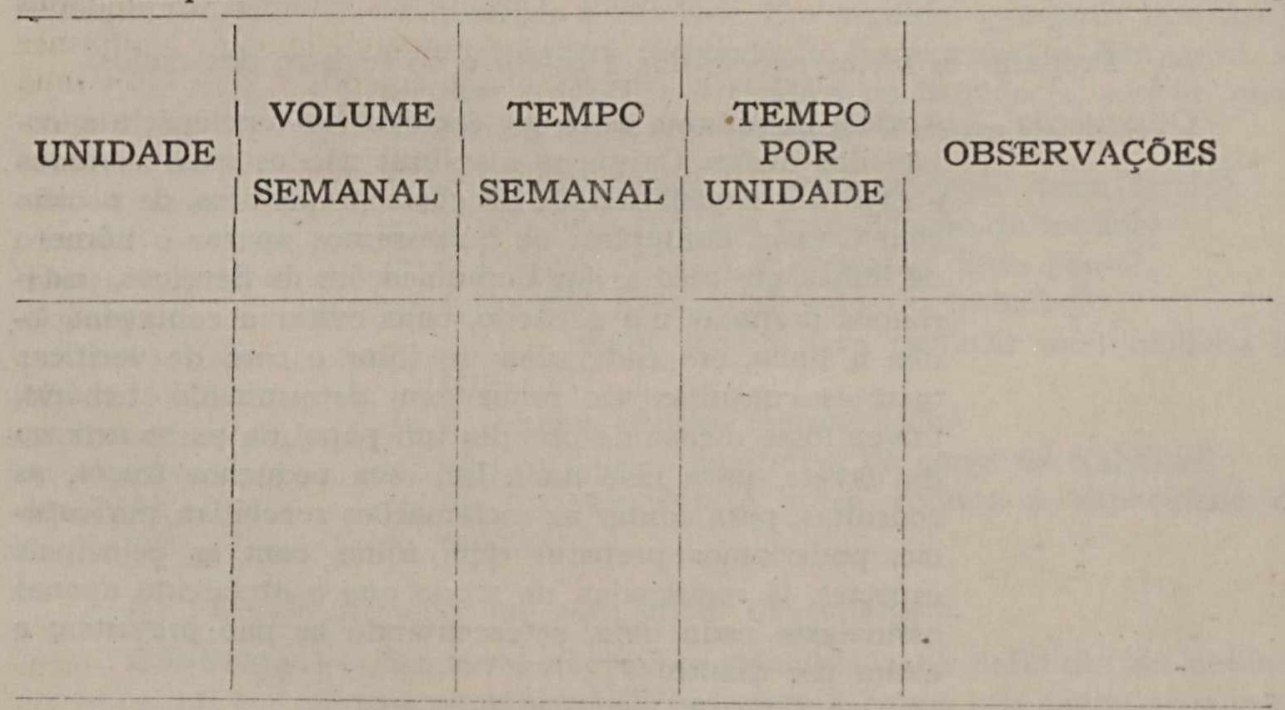


b) Indicar na coluna de Observações o período coberto pela contagem, bem como outros esclarecimentos sôbre a maneira como foram obtidos os dados, quando necessário.

\section{3 - COMO ANALISAR DISTRIBUIÇÃO E SEQÜÊNCIA EM FUNÇÃO DO VOLUME}

Ao analisar o QUADRO DE DISTRIBUIÇÃO DO TRABALHO (QDT) o chefe formula várias hipóteses sôbre possibilidades de simplificação; faz o mesmo quando analisa o GRÁFICO DE SEQUENCIA de cada uma das principais rotinas. A fim de comprovar mais objetivamente essas hipóteses, coleta dacos de volume.

De posse dêsses dados de volume, convenientemente classificados e resumidos num quadro estatístico, voltará o chefe a examinar as questões ou hipóteses prèviamente formuladas, a fim de decidir sôbre as simplificações a introduzir nos métodos de trabalho.

Os exemplos a seguir ilustram, de maneira geral, como se faz a análise da distribuição e da seqüência em função do volume. Êsses exemplos cobrem apenas algumas questões mais freqüentes que podem apresentar-se ao chefe.

1. Como analisar a distribuição da carga de trabalho.

Exemplo I - Eis um caso em que havia desequilíbrio da carga de trabalho em virtude de oscilação diária do volume. 0 registro de documentos, remetidos ao setor de arquivo está afeto a três funcionários, cada um com uma espécie (correspondência, processos e documentos diversos). O Chefe do setor notou certo desequilíbrio na carga de trabalho diária dêsses funcionários; ora, um, ora outro, parecia, em certos dias, estar muito assoberbado de serviço, enquanto noutro parecia "esticar" o trabalho até ao fim do expediente. A estatística semanal de unidades registradas mostrava totais aproximadamente uniformes pelas três especiais. Resolveu, então, o Chefe fazer uma apuração diária, pedindo aos funcionários que anotassem, no fim de cada dia, o total de documentos registrados na respectiva espécie (no caso, os registros existentes não permitiam uma apuração em base diária). Com base nesse levantamento, o Chefe apurou a oscilação diária na carga de trabalho de cada funcionário, e estabeleceu um esquema segundo o qual tôda vez que um funcionário recebesse uma quantidade de documentos além de certo limite, enquanto que outro recebesse aquém do limite, êste auxiliaria aquêle. Dessa forma, os três funcionários passaram a realizar diàriamente uma quantidade uniforme de registros.

Exemplo II - O caso a seguir refere-se a desequilíbrio provocado por trabalho em "ondas". Num setor de comunicações ocorria que os funcionários da turma de recebimento da 
correspondência ficavam sobrecarregados durante as primeiras horas do expediente, e pràticamente sem serviço nas últimas horas do dia. Por outro lado, com os funcionários da turma de expediente ocorria a situação inversa, isto é, quase nenhum trabalho no comêço e muito no fim do expediente. A análise do volume mostrou que as duas "ondas" ocorriam das onze às quatorze horas, e das quinze às dezessete horas.

A solução adotada foi a de colocar os funcionários das duas turmas trabalhando em conjunto nas horas do acúmulo de serviço. Com isso se reduziu consideràvelmente o tempo de recebimento e de expedição.

Exemplo III - Certa Seção adotou a distribuição da tarefa de revisão de processos à base de grupos de Órgãos Locais. Três funcionários faziam essa revisão. Verificava-se o inconveniente de um funcionário estar muito ocupado certos dias, enquanto que em outros entravam poucos processos procedentes de seu grupo de Órgãos.

Medida essa oscilação, através de contagem de casos diários de cada funcionário, ficou reconhecida a inconveniência da divisão em base regional. O novo esquema de distribuição do trabalho que passou a ser adotado consiste em encaminhar, diàriamente, uma quantidade uniforme de processos a cada um dos três funcionários, seja qual fôr o Órgão Local de procedência.

2. Como avaliar a conveniência de consolidar tarefas dispersas.

Exemplo - Em certa Seção existia a seguinte distribuição de tarefas:

Funcionário 1: registrar e arquivar documentos da espécie "A";

Funcionário 2: registrar e arquivar documentos da espécie "B";

Funcionário 3: registrar e arquivar documentos da espécie "C";

Pelos registros existentes o Chefe contou o número de casos de cada espécie, apurando que os funcionários 1 e 2 estavam muito sobrecarregados de serviço, enquanto que o funcionário 3 tinha pouco serviço, pois a espécie "C" apresentava volume que se reduzira em decorrência de modificação nas instruções.

Em face dessa contagem, o Chefe concluiu pela possibilidade de atribuir ao funcionário 3 a tarefa de arquiva- 
mento das três espécies de documentos, ficando o número 1 apenas com o registro da espécie "A" e o n. ${ }^{\circ} 2$ com o registro das espécies " $\mathrm{B}$ " e " $\mathrm{C}$ ".

3. Como verificar a necessidade de determinado passo.

Exemplo - Em certa Delegacia fôra instituído um sistema de recibos para o trânsito interno de papéis. Cada papel que passava de um funcionário para outro, até na mesma Seção, dava origem a uma papeleta que ia ao setor de comunicações, para registro do movimento do papel.

Tal sistema havia sido criado em virtude de estarem ocorrendo casos de desaparecimento de papéis com certa freqüência.

Observou-se que o sistema apresentava dois grandes inconvenientes. Primeiro, continuavam a ocorrer dificuldades, de vez em quando, na localização de papéis. Segundo, era muito trabalhoso. Foi solicitado a cada setor que anotasse, durante certo período, o número de casos de desaparecimento de papéis. Verificou-se, então, que o número de casos era tão reduzido que valia a pena aceitar o risco, e acabar com o contrôle. O caso era, bàsicamente, de definição de rotinas e de arrumação de gavetas, em vez de criação de contrôles. Casos como êstes são muito freqüentes em diferentes tipos de serviços, particularmente nos que envolvem duplicidade de conferências.

4. Como avaliar a conveniência de segregar determinadas espécies ou exceções.

Exemplo I - Em certa rotina os documentos passavam pelo encarregado de um fichário, com base no qual era registrada em certos documentos a referência de antecedentes. Feita uma contagem do número de registro, apurou-se que em apenas $10 \%$ dos documentos era cabível o registro da referência de antecedentes. Por outro lado, verificou-se que os documentos nessa situação poderiam ser separados fàcilmente pelo encarregado de execução do passo anterior da rotina. Nessas condições, em vez de receber e compulsar todos os documentos, o encarregado do fichário passou a receber apenas $10 \%$ dos casos, em média, utilizando o tempo economizado em outras tarefas.

Exemplo II - Os funcionários conferentes de comprovantes de assistência patronal anotavam as falhas em papeletas, encaminhavam estas ao oficial administrativo, a fim de que êste redigisse correspondência. Fêz-se uma contagem dos tipos de correspondência, em função da dificuldade e impor- 
tância, e apurou-se que menos de $7 \%$ justificava a interferência de um oficial administrativo, podendo os $93 \%$ restantes ser redigidos pelos próprios conferentes, por processo manual. Medida, assim, a extensão dos casos excepcionais, pôde o Chefe da Seção calcular o tempo disponível do oficial administrativo para tarefas mais importantes.

5. Como verificar a possibilidade de uniformizar o fluxo do trabalho.

Exemplo - O seguinte caso ilustra uma ocorrência freqüente em muitas rotinas. Os papéis vão transitando normalmente de uma fase para outra, mas em determinado ponto ficam como que represados. (Freqüentemente, a mesa de um Chefe "absorvente constitui um "gargalo"). Determinado processo tem, entre outros, os seguintes passos:
A - recebe; registra
B - verifica antecedentes; informa;
C - calcula importância do auxílio; informa;
D

O Chefe verificou que havia sempre acúmulo de processos em C, enquanto que nos outros executores da rotina os processos demoravam pouco. Feito um estudo do volume, a conclusão foi de que o tempo para cálculo era quase o dôbro do exigido pelos passos a cargo de A e B. A fim de assegurar um fluxo uniforme do trabalho, o Chefe fêz uma redistribuição de tarefas, ficando a parte de cálculo a cargo de C e B (meio tempo). 